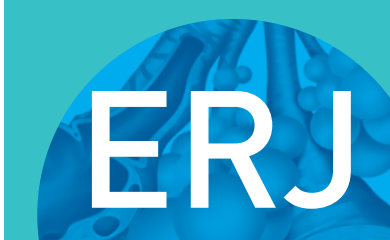

open research

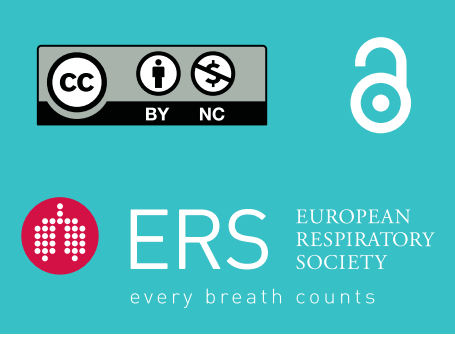

\section{Pubertal-onset overweight and COPD in men: a cohort study}

\author{
To the Editor:
}

A global obesity epidemic has occurred among both adults and children during the last three decades [1]. Among patients with chronic obstructive pulmonary disease (COPD), low body mass index (BMI) is associated with poor prognosis and excess mortality [2], while obesity appears protective [3], a phenomenon known as the obesity paradox. Still, in milder forms of COPD, obesity is associated with increased risk of mortality, possibly mediated via the strong association with diabetes and hypertension [4]. Furthermore, abdominal fat accumulation is the strongest predictor of lung function impairment [5], and abdominal circumference is almost twice as high in COPD patients as in sex- and age-matched controls [6]. Thus, previous studies on the relationship between BMI and COPD have evaluated the associations for adult BMI, while it is unknown if BMI during childhood or adolescence, i.e. many years before onset of COPD, predicts the development of COPD later in life.

The aim of the present study was therefore to determine if overweight established during childhood or puberty, many years before the COPD diagnosis, affects the risk of developing COPD.

In BEST (BMI Epidemiology Study) Gothenburg, we collected birth weight as well as measurements of height and weight from centrally archived School Health Care records and from military conscription tests for all men born between 1945 and 1961 in Gothenburg, Sweden, as previously described [7]. The main exposures were childhood BMI at 8 years of age and young adult BMI at 20 years of age [7], and childhood and young adult overweight $\left(\mathrm{BMI} \geqslant 17.9[8]\right.$ or $\geqslant 25 \mathrm{~kg} \cdot \mathrm{m}^{-2}$, respectively). Pubertal BMI change was calculated (BMI at $20-$ BMI at 8 years of age). We retrieved the study subjects' highest achieved education level during the years 1990-2012, categorised as low, medium or high, from registers held by Statistics Sweden. Through linkage to the National Patient Register held by the National Board of Health and Welfare, Sweden, we obtained information on COPD diagnosis coded according to the International Classification of Diseases (ICD) system and defined as J44 in ICD10 or 496 in ICD9 as the main or auxiliary diagnosis. The 37670 men included in the study were followed from 20 years of age until censoring due to a COPD diagnosis $(n=672)$, migration $(n=2745)$, death $(n=3929)$ or until 31 December 2016, whichever came first. Hazard ratios (HRs) and 95\% confidence intervals were estimated by Cox regressions including birth year and country of birth (categorised as Sweden if the subject and both parents were born in Sweden, or other) as covariates. The statistical analyses were performed in SPSS (version 24; IBM, Armonk, NY, USA).

The ethics committee of the University of Gothenburg, Sweden, approved the study.

In this population-based study, 37670 men with information on both childhood BMI at age 8 years $\left(\right.$ mean \pm SD $15.7 \pm 1.4 \mathrm{~kg} \cdot \mathrm{m}^{-2}$ ) and BMI change during puberty (BMI at age $20-$ BMI at age 8 years; $5.6 \pm 2.0 \mathrm{~kg} \cdot \mathrm{m}^{-2}$ ) were included and followed until 31 December 2016. Mean follow-up starting from 20 years of age was 40.2 years (1512923 person-years of follow-up). There were 672 cases of COPD before the end of follow-up and the mean age at diagnosis was $58.9 \pm 6.1$ years.

Cox regression analyses did not reveal a significant association between childhood BMI at 8 years of age and risk of a COPD diagnosis. However, BMI change during puberty displayed a significant nonlinear association with risk of COPD ( $\mathrm{p}$-value for quadratic term $<0.05$ ).

@ERSpublications

Men who develop overweight specifically during puberty (i.e. normal weight at age 8 , overweight at age 20 years) have $70 \%$ increased risk of COPD as adults compared to men without overweight http://bit.ly/2TradZA

Cite this article as: Tengvall S, Ohlsson C, Bygdell M, et al. Pubertal-onset overweight and COPD in men: a cohort study. ERJ Open Res 2020; 6: 00326-2019 [https://doi.org/10.1183/23120541.003262019].

Copyright $\odot$ ERS 2020. This article is open access and distributed under the terms of the Creative Commons Attribution NonCommercial Licence 4.0. 
Whereas childhood overweight $(\mathrm{n}=2357)$ was not associated with the risk of COPD later in life (HR 1.00, 95\% CI $0.73-1.37)$, young adult overweight $(n=2788)$ demonstrated a significant association with the risk of COPD (HR 1.49, 95\% CI 1.15-1.93). To determine the importance of timing of onset of overweight, we analysed the risk of COPD for four combinations of normal weight/overweight status at childhood and young adult age. These analyses demonstrated that men who developed overweight during puberty (i.e. normal weight at 8 , overweight at 20 years) had a substantially increased risk of COPD (HR 1.72, 95\% CI 1.28-2.32) compared with men who were never overweight (table 1). In contrast, men with childhood-onset overweight that resolved during puberty (i.e. overweight at 8, normal weight at 20 years), and men with childhood-onset overweight who were persistently overweight throughout childhood and puberty (i.e. overweight at 8 and 20 years of age) did not have a significantly increased risk of adult COPD compared with men who were never overweight (table 1). Unfortunately, the analyses could not be adjusted for smoking as information on smoking was not available in this retrospective study. When we adjusted the association between overweight status and risk of COPD for the individuals' maximal education level, we found unaltered results compared to before adjustment (table 1). Similar results were also seen after adjustment for birthweight, and in the subgroup of subjects with Sweden as country of birth for the subject and both parents (table 1).

Thus, our findings suggest that pubertal-onset overweight is associated with $>70 \%$ increased risk of developing COPD compared with men who were never overweight.

We have previously observed that BMI increase specifically during puberty is associated with the amount of visceral adipose tissue [9] in men. COPD patients have excessive visceral fat mass that is retained in patients with more advanced stages of COPD despite normal or underweight status [10]. A potential mechanistic link between visceral adipose tissue and COPD probably includes proinflammatory adipokines such as leptin released by adipocytes in response to tissue hypoxia [10]. Based on the findings in the present study, we speculate that visceral fat is involved in the mediation of the association between pubertal-onset overweight and the observed risk of COPD.

\section{TABLE 1 Risk of COPD in relation to overweight status at childhood and at young adult age}

\begin{tabular}{|c|c|c|}
\hline Childhood/young adult overweight status & Cases of COPD & $\operatorname{HR}(95 \% \mathrm{CI})$ \\
\hline \multicolumn{3}{|l|}{ Base model } \\
\hline Normal weight/normal weight ( $n=33514$ ) & 585 & Ref. \\
\hline Overweight/normal weight $(n=1368)$ & 23 & $1.00(0.66-1.51)$ \\
\hline Normal weight/overweight ( $n=1799)$ & 47 & $1.72(1.28-2.32)$ \\
\hline Overweight/overweight (n=989) & 17 & $1.08(0.67-1.75)$ \\
\hline \multicolumn{3}{|l|}{ Model adjusted for education level } \\
\hline Normal weight/normal weight (n=32523) & 585 & Ref. \\
\hline Overweight/normal weight ( $\mathrm{n}=1334$ ) & 23 & $1.13(0.75-1.72)$ \\
\hline Normal weight/overweight ( $n=1753$ ) & 47 & $1.52(1.12-2.04)$ \\
\hline Overweight/overweight (n=961) & 17 & $1.02(0.63-1.65)$ \\
\hline \multicolumn{3}{|l|}{ Model adjusted for birthweight } \\
\hline Normal weight/normal weight $(n=31714)$ & 542 & Ref. \\
\hline Overweight/normal weight ( $\mathrm{n}=1292)$ & 21 & $1.05(0.68-1.63)$ \\
\hline Normal weight/overweight ( $n=1713$ ) & 42 & $1.67(1.22-2.29)$ \\
\hline Overweight/overweight $(\mathrm{n}=941)$ & 16 & $1.12(0.68-1.84)$ \\
\hline \multicolumn{3}{|l|}{ Subcohort with Sweden as country of birth } \\
\hline Normal weight/normal weight ( $\mathrm{n}=27979)$ & 496 & Ref. \\
\hline Overweight/normal weight $(\mathrm{n}=1138)$ & 20 & $1.03(0.66-1.61)$ \\
\hline Normal weight/overweight $(n=1469)$ & 40 & $1.72(1.25-2.37)$ \\
\hline Overweight/overweight $(n=821)$ & 12 & $0.92(0.52-1.63)$ \\
\hline
\end{tabular}

Hazard Ratios (HRs) for COPD were calculated using Cox proportional hazards regression. All models were adjusted for birth year and country of birth. Base model: entire cohort, $n=37670$ ). Model adjusted for maximal education level: $n=36571$; categorised as low ( $n=6647,17.6 \%)$, medium ( $n=16213,43.0 \%$ ) or high ( $n=13711,36.4 \%$ ). Model adjusted for birthweight: $n=35660$. Subcohort of subjects born in Sweden and with parents born in Sweden: $n=31407$. Normal weight/normal weight: not overweight at 8 or 20 years of age; overweight/normal weight: overweight at 8 but not at 20 years of age; normal weight/overweight: overweight at 20 but not at 8 years of age; overweight/overweight: overweight both at 8 and 20 years of age. Childhood overweight at 8 years of age was defined as body mass index (BMI) $\geqslant 17.9 \mathrm{~kg} \cdot \mathrm{m}^{-2}$ while young adult overweight at 20 years of age was defined as $B M I \geqslant 25 \mathrm{~kg} \cdot \mathrm{m}^{-2}$. 
The strengths of the present study include the well-powered cohort, and the long and nearly complete follow-up in Swedish registers. A COPD diagnosis in the National Patient Register in Sweden has good validity as compared with medical records [11]. The limitations include that COPD diagnoses were captured through hospital-based registers, thus overlooking patients who were never treated at a hospital but only in primary care, resulting in a lower prevalence of COPD than expected. Furthermore, we do not have information on tobacco smoking or measurement of visceral fat. Given the fact that tobacco smoking is the major contributor to development of COPD in adults in industrialised countries, the lack of information on smoking is a clear limitation. It has been highlighted that never-smokers comprise a substantial proportion of individuals with COPD [12, 13], and there is a strong relationship between prevalence of COPD and obesity among adult never-smokers [14]. These findings indicate that obesity may be a risk factor for COPD in nonsmokers.

The observational nature of our study precludes making conclusive statements about the observed associations and the lack of adjustment for smoking makes the results more uncertain. Our findings could, however, be useful for hypothesis generation.

In conclusion, we demonstrate that pubertal-onset overweight is associated with $>70 \%$ higher risk of developing COPD later in life in Swedish men. Future studies are needed to elucidate the mechanisms behind this finding, and the possible link between visceral fat and the risk of developing COPD.

\section{Sara Tengvall ${ }^{1,7}$, Claes Ohlsson ${ }^{2,3,7}$, Maria Bygdell ${ }^{2}$, Jari Martikainen ${ }^{4}$, Anders Andersson ${ }^{5}$ and Jenny M. Kindblom ${ }^{2,6}$ \\ ${ }^{1}$ Närhälsan, Frölunda Vårdcentral, Gothenburg, Sweden. ${ }^{2}$ Centre for Bone and Arthritis Research, Institute of Medicine, Sahlgrenska Academy at University of Gothenburg, Gothenburg, Sweden. ${ }^{3}$ Region Västra Götaland, Sahlgrenska University Hospital, Dept of Drug Treatment, Gothenburg, Sweden. ${ }^{4}$ Bioinformatics Core Facility, Sahlgrenska Academy, University of Gothenburg, Gothenburg, Sweden. ${ }^{5}$ COPD Center, Institute of Medicine, Sahlgrenska University Hospital, University of Gothenburg, Gothenburg, Sweden. ${ }^{6}$ Region Västra Götaland, Sahlgrenska University Hospital, Pediatric Clinical Research Center, Gothenburg, Sweden. ${ }^{7}$ These authors contributed equally.}

Correspondence: Jenny M. Kindblom, Klinfarmlab, Vita Stråket 11, Sahlgrenska University Hospital, S41345 Gothenburg, Sweden. E-mail: jenny.kindblom@gu.se

Received: 7 Aug 2019 | Accepted after revision: 27 Dec 2019

Conflict of interest: S. Tengvall has nothing to disclose. C. Ohlsson has nothing to disclose. M. Bygdell has nothing to disclose. J. Martikainen has nothing to disclose. A. Andersson reports lectures in pulmonary medicine outside this work for AstraZeneca and Novartis. J.M. Kindblom has nothing to disclose.

Support statement: This study was supported by the Swedish Research Council and the Heart-Lung Foundation, and by grants from the Swedish state under the agreement between the Swedish government and the county councils (the ALF-agreement; 723791, 238261), the Lundberg Foundation, the Torsten Söderberg Foundation, the Novo Nordisk Foundation, and the Knut and Alice Wallenberg Foundation. Funding information for this article has been deposited with the Crossref Funder Registry.

\section{References}

1 Finucane MM, Stevens GA, Cowan MJ, et al. National, regional, and global trends in body-mass index since 1980 systematic analysis of health examination surveys and epidemiological studies with 960 country-years and 9.1 million participants. Lancet 2011; 377: 557-567.

2 Schols AM, Slangen J, Volovics L, et al. Weight loss is a reversible factor in the prognosis of chronic obstructive pulmonary disease. Am J Respir Crit Care Med 1998; 157: 1791-1797.

3 Landbo C, Prescott E, Lange P, et al. Prognostic value of nutritional status in chronic obstructive pulmonary disease. Am J Respir Crit Care Med 1999; 160: 1856-1861.

4 Verberne LDM, Leemrijse CJ, Swinkels ICS, et al. Overweight in patients with chronic obstructive pulmonary disease needs more attention: a cross-sectional study in general practice. NPJ Prim Care Respir Med 2017; 27 : 63.

5 Leone N, Courbon D, Thomas F, et al. Lung function impairment and metabolic syndrome: the critical role of abdominal obesity. Am I Respir Crit Care Med 2009; 179: 509-516.

6 Marquis K, Maltais F, Duguay V, et al. The metabolic syndrome in patients with chronic obstructive pulmonary disease. J Cardiopulm Rehabil 2005; 25: 226-232.

7 Ohlsson C, Bygdell M, Sonden A, et al. Association between excessive BMI increase during puberty and risk of cardiovascular mortality in adult men: a population-based cohort study. Lancet Diabetes Endocrinol 2016; 4: 1017-1024.

8 Kuczmarski RJ, Ogden CL, Guo SS, et al. 2000 CDC Growth Charts for the United States: methods and development. Vital Health Stat 11 2002; 1-190.

9 Kindblom JM, Lorentzon M, Hellqvist A, et al. BMI changes during childhood and adolescence as predictors of amount of adult subcutaneous and visceral adipose tissue in men: the GOOD Study. Diabetes 2009; 58: 867-874. 
10 Furutate R, Ishii T, Wakabayashi R, et al. Excessive visceral fat accumulation in advanced chronic obstructive pulmonary disease. Int J Chron Obstruct Pulmon Dis 2011; 6: 423-430.

11 Inghammar M, Engstrom G, Lofdahl CG, et al. Validation of a COPD diagnosis from the Swedish Inpatient Registry. Scand J Public Health 2012; 40: 773-776.

12 Lamprecht B, McBurnie MA, Vollmer WM, et al. COPD in never smokers: results from the population-based burden of obstructive lung disease study. Chest 2011; 139: 752-763.

13 Perez-Padilla R, Fernandez R, Lopez Varela MV, et al. Airflow obstruction in never smokers in five Latin American cities: the PLATINO study. Arch Med Res 2012; 43: 159-165.

14 Fuller-Thomson E, Howden KEN, Fuller-Thomson LR, et al. A Strong Graded Relationship between Level of Obesity and COPD: Findings from a National Population-Based Study of Lifelong Nonsmokers. J Obes 2018; 2018: 6149263 . 